\title{
On selective indirect tax reform in developing countries
}

\author{
M. Shahe Emran, ${ }^{\mathrm{a}, \mathrm{b}, \mathrm{c}, *}$, Joseph E. Stiglitz ${ }^{\mathrm{c}, \mathrm{d}}$ \\ ${ }^{a}$ Department of Economics, George Washington University, Funger 638, 2201 G Street, \\ N.W. Washington, DC 20052, United States \\ ${ }^{\mathrm{b}}$ ESIA, George Washington University, United States \\ ${ }^{\mathrm{c}} I P D$, Columbia University, United states \\ ${ }^{\mathrm{d}}$ Department of Economics, Columbia University, United States
}

Received 30 December 2001; received in revised form 31 March 2004; accepted 12 April 2004

Available online 18 September 2004

\begin{abstract}
The current consensus on indirect tax reform in developing countries favors a reduction in trade taxes with an increase in VAT to raise revenue. The theoretical results on selective reform that underlie this consensus are, however, derived from partial models that ignore the existence of an informal economy. Once the incomplete coverage of VAT due to an informal economy is acknowledged, we show that, contrary to the current consensus, the standard revenue-neutral selective reform of trade taxes and VAT reduces welfare under plausible conditions. Moreover, a VAT base broadening with a revenue-neutral reduction in trade taxes may also reduce welfare. The results raise serious doubts about the wisdom of the indirect tax reform policies pursued by a large number of developing countries. (C) 2004 Elsevier B.V. All rights reserved.
\end{abstract}

\section{Introduction}

Over the last few decades, a general consensus regarding the indirect tax reform in developing countries has emerged that spans academic economists and policy practitioners

* Corresponding author. Tel.: +1 202994 6922; fax: +1 2029947743.

E-mail address: shahe_emran@hotmail.com (M.S. Emran). 
alike. A reduction in the trade tax with a compensating or revenue-enhancing increase in value-added tax (henceforth VAT) has been the center-piece of such a reform, ${ }^{1}$ and it has been implemented in a large number of developing countries under the structural adjustment and stabilization policy conditionalities of the IMF and the World Bank. ${ }^{2}$ The virtues of a consumption tax like VAT are well-known: the elimination of cascading (compared to a turnover tax), and of undue protection to the domestic production of import substitutes (compared to an import tariff), to mention a couple. The trade taxes, on the other hand, are, generally, looked upon as doubly distortionary as they interfere with both consumer and producer prices. There is, however, an important structural feature of a developing country that militates against the desirability of VAT: the existence of a large informal sector that escapes the VAT net. ${ }^{3}$ This implies that while a radial (across the board) uniform reduction in trade taxes reduces the production distortions and the distortions between tradable and nontradable sectors, a revenue-neutral radial increase in VAT increases the inter-sectoral distortions between formal and informal sectors (see Emran and Stiglitz, 2000a). As a result, contrary to the prevailing consensus, such a reform reduces welfare under plausible conditions. It casts strong doubts on the validity of the current consensus regarding indirect tax policy reform in developing countries, when the reform under consideration is a comprehensive one (radial reform). This, however, leaves open the question of the desirability of a selective indirect tax reform along the lines frequently prescribed by the IMF and the World Bank. ${ }^{4}$ The objective of this paper is to address this issue by extending the analysis to the case of a selective reform of trade tax and VAT in an economy with an informal sector. More precisely, we consider a reduction in the import tariff or export tax on a given commodity (say commodity $k$ ) with a revenueneutral increase in the VAT on another commodity (say commodity $i$ ). The economic costs of a change in the tax on any given commodity depends on its interrelationships in consumption and production with all other commodities in the economy, both formal and informal. While a reduction in the trade tax on commodity $k$ reduces the inter-commodity distortions in both consumption and production relative to all other commodities (including $i$ ) in the economy, a revenue-neutral increase in the VAT on $i$ increases the

\footnotetext{
${ }^{1}$ Among few dissenting views, see Anderson $(1996,1999)$ who shows that it is almost impossible to ensure welfare improvement from a radial revenue-neutral reform of trade taxes and consumption taxes when nontradables are allowed in the model.

2 As of April 2001, 123 countries have some form of VAT. The spread of VAT in developing countries has been dramatic over the decade of 1990s. In 1969, only one country in Sub-Saharan Africa had VAT. The number increased to four over next two decades. As of April 2001, there are now 27 Sub-Saharan African countries with VAT (for a recent discussion of the evolution and spread of VAT, see Ebrill et al., 2001).

3 The informal sector is defined in this paper to be that part of the economy which escapes commodity tax coverage. It usually includes agriculture, rural non-farm activities (accounted for in the GDP) along with the socalled shadow economy. The recent estimates show that the average size of the shadow economy over 1989-1993 as a percentage of GDP is 39\% for developing countries and is $12 \%$ for OECD countries. When measured in terms of labor force employed in the shadow economy as a percentage of official labor force in 1997-1998, the average is $50.1 \%$ for developing countries and $17.3 \%$ for OECD countries. In some developing countries like Nigeria and Egypt, the average size of the shadow economy over the period 1990-1993 is 68-76\% of GDP (see Schneider and Enste, 2000).

${ }^{4}$ When the tax changes apply only to a subset of the commodities under the tax net, it is called Selective Reform.
} 
distortions in consumption, again relative to all other commodities (including $k$ ). So the logic of inter-sectoral distortions advanced in Emran and Stiglitz (2000a) in the context of a radial reform is not as evident in this case.

The concerns of this paper are thus at the intersection of two related issues: (i) the inefficiencies of VAT due to an informal sector and (ii) the design of selective reform of taxes and tariffs in a revenue-constrained second best world. While there is a large and mature literature on the piecemeal ${ }^{5}$ reform of tariffs and/or taxes, the inefficiencies caused by the incomplete coverage of VAT due to an informal economy has largely been neglected in the literature, with the notable exception of a recent contribution by Piggott and Whalley (2001). Piggott and Whalley (2001) construct simple numerical examples of a general equilibrium economy, where a VAT base broadening reduces welfare because of supply side substitutions toward informal and home production (self supply). Results from calibration of their model to the data from Canada show that the base broadening of VAT has, in fact, reduced aggregate efficiency. Our analysis differs from theirs both in terms of the questions we address and the models we use. While Piggott and Whalley (2001) confine their analysis to the implications of an informal sector for a VAT base broadening, with empirical evidence from a developed country, our focus is on a revenue-neutral reform of VAT and trade tax in the presence of a large informal economy, particularly in the context of developing countries. We analyze both a revenue-neutral selective reform of VAT and trade tax on the existing bases (in the tradition of piecemeal reform literature) and a VAT base broadening with a revenue-neutral reduction in trade taxes. We assume that the formal and informal sectors produce different commodities (imperfect substitutes), which is a more general formulation with the assumption of perfect substitutes entertained by Piggott and Whalley as a special case.

The literature on the piecemeal reform of import tariffs (and indirect taxes, in general) has a long and venerable pedigree. Starting from the seminal work of Bertrand and Vanek (1971) on the concertina theorem that formalizes an intuition originally due to Meade (1955), the literature has focused on establishing sufficient conditions for welfare improvement from piecemeal reform of tariffs and or taxes, with and without an active government budget constraint ${ }^{6}$ (see Hatta, 1977, 1986; Diewert et al., 1989; Michael et al., 1993; Abe, 1995; Anderson, 1999, among others). ${ }^{7}$ In the face of difficult fiscal predicament of governments in developing countries, and given the evidence that trade tax reform is likely to result in significant loss of revenue, ${ }^{8}$ the objective in the recent literature has been to devise strategies for reforming taxes and tariffs in a way that both preserves

\footnotetext{
5 The piecemeal reform includes both a radial (across the board) uniform reform and a selective reform.

6 The government budget constraint is said to be active when a reduction in the revenue due to a reduction in one tax needs to be balanced by an offsetting increase in another distortionary tax. The concertina theorem says that, starting from an arbitrary tariff structure, it is welfare-improving to reduce the highest tariff to the second highest and so on under the assumption of substitutability, when the budget is balanced passively through adjustments in lump-sum transfers.

7 In an interesting paper, Lopez and Panagariya (1992) show that it is impossible to satisfy the substitutability assumption underlying the concertina theorem when there are pure intermediate imports (zero domestic production) in the economy.

${ }^{8}$ The recent estimates based on CGE models for sixty countries show that trade liberalization reduces government revenue (see Devarajan et al., 1999).
} 
revenue-neutrality and improves national welfare. In the context of selective reform, Michael et al. (1993) show that, in a tradables-only economy with no informal sector, a reduction in the import tariff on the commodity bearing the highest tariff and also the highest total indirect tax burden increases welfare under suitable assumptions of substitutability, when the lost revenue is compensated for by an increase in the consumption tax on the commodity bearing the lowest indirect tax burden. The extant literature, however, completely ignores the implications of an informal economy for the efficiency of consumption tax (VAT) as an instrument of revenue-raising, which can be especially important in the developing countries. An assumption critical for the validity and applicability of the existing results on revenue-neutral selective reform of tariffs and consumption taxes is that it is feasible to impose and collect consumption tax (VAT) on the commodity bearing the lowest indirect tax on consumption. While this assumption is automatically satisfied when an economy consists of only the formal sector, it is not a plausible assumption in the presence of a large informal segment in the economy that, by definition, escapes VAT coverage. In an economy with both formal and informal sectors, the best one can do is to select the commodity enjoying the lowest indirect tax burden among the subset of formal commodities as the candidate for VAT increase. Once this restriction placed by the incomplete coverage of VAT is acknowledged, we show that there are plausible (sufficient) conditions under which such a selective reform of VAT and import tariff reduces welfare. Consistent with the numerical results of Piggott and Whalley, we also provide plausible sufficient conditions for worsening of welfare from a reduction in import tariff with a revenue-neutral VAT base broadening. Also, the extant literature almost exclusively deals with the coordinated reform of import tariffs and consumption taxes, and ignores the case of a coordinated reform of export taxes and consumption taxes, although such reforms are frequently prescribed by the policy advisors. Our results on export tax reform in the absence of an informal sector show that the conditions required for a welfare improvement from the reduction in export tax on one commodity with a revenueneutral increase in VAT on another are much more stringent than the case of an import tariff reform. Unlike the case of an import tariff reform, the selective revenue-neutral reform of VAT and export tax can reduce welfare in an economy without an informal sector, even when all commodities are pair-wise substitutable. ${ }^{9}$ The results of this paper thus complement and strengthen the conclusions reached by Emran and Stiglitz (2000a) in the context of a radial uniform reform of VAT and trade taxes: the current consensus about the indirect tax reform is built on fragile results derived from a partial model that ignores the existence of an informal sector; and the results from a more complete model demonstrates that such a reform can reduce welfare under plausible assumptions.

The rest of the paper is structured as follows. The first section presents the basic model of the economy. In Section 2, we analyze the case of a revenue-neutral reform of import tariff and VAT. The next section is devoted to the case of a revenue-neutral reform of export tax and VAT. In each case, we consider both a selective reform and a revenueneutral VAT base broadening, and derive sufficient conditions for a welfare-worsening

\footnotetext{
9 The results on the export tax reform without an informal economy reported in this paper are, to the best of our knowledge, new contributions.
} 
reform. The paper concludes with some remarks about the likely implications of some factors omitted from the model for the validity of the results.

\section{The model}

We build the analysis on a simple model of the economy which has been the workhorse in the literature on tax and tariff policy reform. The economy, endowed with a vector of fixed factors $(L)$, is a competitive small open economy. It is assumed that there are no nontradable commodities. ${ }^{10}$ All of the commodities are consumed and produced domestically and are also internationally traded. The set of commodities can be partitioned into four subsets depending on whether a commodity is produced in the formal or informal sector, and on whether it is an exportable or an importable. We use $x$ for the set of exportables, $m$ for the set of importables, $f$ for the set of commodities produced in the formal sector and $s$ for the set of commodities produced in the informal sector. The set of all commodities, i.e., the union set of exportables and importables, is denoted as $T$. The subset $x f(x s)$ consists of all the exportables produced in the formal (informal) sector. Analogously, $m f(m s)$ denotes the subset of importables produced in formal (informal) sector. There are some goods, which are not taxable. For simplicity, we lump together all the non-taxable goods into a single good and assume it to be an informal exportable. This non-taxable informal exportable serves as the numeraire, and is denoted as commodity ' 0 '. ${ }^{11}$ There is a representative consumer who owns all the factors of production and maximizes a strictly quasiconcave utility function subject to the budget constraint. Let $E\left(q_{0}, q, U\right)$ denote the expenditure function. So $E($.$) is the minimum expenditure needed to achieve utility$ level $U$ facing the consumer price vector $\left[q_{0}, q\right]$. The production side of the economy is represented by a revenue function $G\left(p_{0}, p, L\right)$, which shows the maximum value of the national output produced with factors $L$ and a convex technology when facing the producer price vector $\left[p_{0}, p\right]$. Pure profits, when they exist due to diminishing returns, are assumed to be untaxed. ${ }^{12}$ This implies that the assumption of an untaxed numeraire places restrictions on the set of admissible taxes. $G\left(p_{0}, p, L\right)$ is assumed to be strictly convex in $p$ and strictly concave in $L .{ }^{13}$ Both the expenditure and revenue functions are assumed to be twice differentiable. The government raises revenue

${ }^{10}$ The assumption of a tradables-only economy, although widely used, is undoubtedly a strong one. We adopt the assumption on two grounds. First, it helps to compare and contrast our results with those established in the literature. Second, as we discuss later, the inclusion of nontradables is likely to strengthen the conclusions reached in this paper.

11 As is well-known, such normalization does not impose any restrictions on the set of admissible taxes only if either the technology is CRTS or there is $100 \%$ profit tax. As discussed later, we allow for positive profit that cannot be taxed away by government.

12 For well-known reasons, governments in developing countries can not impose $100 \%$ profits tax. For example, it is practically impossible to isolate any pure profit from quasi-rents (the returns to capital and entrepreneurship) in a typical small unincorporated business in developing countries (see Sah and Stiglitz, 1992).

13 The revenue function is strictly convex in $p$ if there are some substitutability between untaxed numeraire and the taxed commodities (see Dixit, 1985, p. 344). 
$(R(\tau, v))$ using the trade taxes $(\tau)$ and VAT $(v)$. The world prices of all the commodities are normalized to unity by suitable choice of units. Since the specific and ad valorem taxes are equivalent in a competitive model, without loss of generality, we concentrate on specific taxes. The price relations in the economy before policy reform are as follows:

$$
\begin{array}{ll}
q^{f}=1+\tau^{f}+v & p^{f}=1+\tau^{f} \\
q^{s}=1+\tau^{s}=p^{s} & p_{0}=q_{0}=1
\end{array}
$$

where $q^{l}$ is the vector of consumer prices, $p^{l}$ the vector of producer prices and $\tau^{l}$ is the vector of trade taxes on commodities produced in sector $l$, with $l=f, s$, and $v$ is the vector of VAT applicable only to the commodities produced in the formal sector. ${ }^{14}$ For simplicity, we assume that there are no direct subsidies on consumption, production or international trade, implying that $v_{j} \geq 0, \forall j \in f ; \tau_{j} \geq 0, \forall j \in m$; and $\tau_{j} \leq 0, \forall j \in x$. We also assume that all the prices in the economy are positive. The total indirect tax burden on consumption of commodity $j$ is denoted as $\beta_{j}$, i.e., $\beta_{j} \equiv v_{j}+\tau_{j}$. where $v_{j}=0$, by definition, $\forall j \in s$. The total indirect tax rate as a proportion of consumer price is denoted as $\theta_{j}$, i.e., $\theta_{j}=\left(\beta_{j} / q_{j}\right)$.

Assuming that the tax revenue is returned to the consumer in a cost-less lump-sum fashion, the private budget constraint of the representative consumer equates the expenditure $E\left(q_{0}, q, U\right)$ with the private revenue or GNP, $G\left(p_{0}, p, L\right)$, plus the tax revenue:

$$
(P B C): E\left(q_{0}, q, U\right)=G\left(p_{0}, p, L\right)+R(\tau, v)
$$

The government budget constraint is given by the following:

$$
(G B C): R(\tau, v) \equiv \tau^{\prime}\left(E_{q}-G_{p}\right)+v^{\prime} E_{q^{f}}=\bar{R}
$$

where the subscripts to the functions $E($.$) and G($.$) denote the partial derivatives, the prime$ denotes a transpose of a vector or of a matrix, $\tau$ denotes the vector of trade taxes on both formal and informal tradables, and the government is assumed to have a fixed revenue requirement $\bar{R}$. In addition to the budget constraints of the consumer and the government, the equilibrium of the economy is characterized by the balance of trade condition, which we can ignore by Walras law. So Eqs. (1) and (2) are the building blocks for analyzing any indirect tax reform in this economy.

\footnotetext{
${ }^{14}$ One might argue that it should be feasible to collect VAT on the internationally traded portion of the informal goods also. If it is feasible to collect tariff, it is also feasible to collect VAT on imports. However, when the competing domestic production in the informal sector can not be taxed by VAT, a tax collected at the border is, in fact, a trade tax, even if it is collected under the heading "VAT". This is so because such a tax drives a wedge between the prices faced by the domestic and international producers and thus can not be considered a consumption tax.
} 
In the tradition of selective policy reform literature, we focus on the following indirect tax reform: a reduction in the trade tax (import tariff or export tax depending on whether it is an importable or an exportable) on commodity $k\left(\tau_{k}\right)$ with a revenue-neutral increase in VAT on commodity $i\left(v_{i}\right){ }^{15}$ The effects of such a reform on the private budget constraint (PBC) and the government budget constraint (GBC) are as follows:

$$
\begin{aligned}
& \left(E_{q_{k}}-G_{p_{k}}\right) \mathrm{d} \tau_{k}+E_{q_{i}^{f}} \mathrm{~d} v_{i}+E_{U} \mathrm{~d} U=0 \\
& {\left[\left(E_{q_{k}}-G_{p_{k}}\right)+v^{\prime} E_{q^{f} q_{k}}+\tau^{\prime}\left(E_{q q_{k}}-G_{p p_{k}}\right)\right] d \tau_{k}+\left[\tau^{\prime} E_{q q_{i}^{f}}+E_{q_{i}^{f}}+v^{\prime} E_{q^{f} q_{i}^{f}}\right] \mathrm{d} v_{i}} \\
& \quad+\left[\tau^{\prime} E_{q U}+v^{\prime} E_{q^{f} U}\right] \mathrm{d} U=0
\end{aligned}
$$

Eq. (4) can be rewritten as below to determine the change in $v_{i}$ needed to offset the revenue loss from a marginal reduction in $\tau_{k}$ :

$$
\frac{\mathrm{d} v_{i}}{\mathrm{~d} \tau_{k}}=\Psi_{i}^{-1}\left\{\Psi_{k}+\left[\tau^{\prime} E_{q U}+v^{\prime} E_{q^{f} U}\right] \frac{\mathrm{d} U}{\mathrm{~d} \tau_{k}}\right\}
$$

where $\Psi_{i}=\tau^{\prime} E_{q q_{i}^{f}}+E_{q_{i}^{f}}+v^{\prime} E_{q^{f} q_{i}^{f}}$ is the marginal effect on the total indirect tax revenue of a change in $v_{i}$ and $\Psi_{k}=\left(E_{q_{k}}-G_{p_{k}}\right)+v^{\prime} E_{q^{f} q_{k}}+\tau^{\prime}\left(E_{q q_{k}}-G_{p p_{k}}\right)$ is the marginal revenue effect of a change in $\tau_{k}$. Since we have assumed that both the taxes are on the "right" side of the Laffer curve, it follows that $\Psi_{i}>0$ and $\Psi_{k}>0$ if $k \in m ; \Psi_{k}<0$ if $k \in x$.

Now dividing Eq. (3) by $\mathrm{d} \tau_{k}$ and using Eq. (5), we get the following equation upon rearranging terms:

$$
\Psi_{k}^{-1} Q \frac{\mathrm{d} U}{\mathrm{~d} \tau_{k}}=E_{q_{i}^{f}} \Psi_{i}^{-1}-\left(E_{q_{k}}-G_{p_{k}}\right) \Psi_{k}^{-1}
$$

where $Q=\left\{E_{U^{-}}-E_{q_{i}^{f}} \Psi_{i}^{-1}\left[\tau^{\prime} E_{q U^{+}}+v^{\prime} E_{q^{f} U}\right]\right\}$. Observe that $q_{0} E_{q_{0} U^{+}}+q^{\prime} E_{q U}=E_{U}$ because $E_{U}$ is homogenous of degree one in $\left[q_{0}, q\right]$. Using this, we can rewrite $Q$ as follows:

$$
Q=q_{0} E_{q_{0} U}+1^{\prime} E_{q U}+\left(1-E_{q_{i}^{f}} \Psi_{i}^{-1}\right)\left[\tau^{\prime} E_{q U}+v^{\prime} E_{q^{f}} U\right]
$$

where 1 is a vector of ones of appropriate dimension. Note that the usual assumption that there are no inferior commodities in the economy is not sufficient for signing the above expression because $\left(1-E_{q_{i}^{f}} \Psi_{i}^{-1}\right)$ is likely to be negative for distortionary taxation, and the vector $\tau$ has both positive (import tariff) and negative (export tax) elements. But considerations of stability and uniqueness of equilibrium dictate that $Q>0$, which we assume in what follows. ${ }^{16}$

15 In this paper, we assume that all the taxes are on the "right" side of the Laffer curve so that a reduction (increase) in rates reduces (increases) revenue. There are ample evidence that a trade reform is not likely to be self-financing and an increase in other taxes is warranted to fill up the revenue gap (see Devarajan et al., op. cit.).

${ }^{16}$ We are essentially invoking the correspondence principle a' la Samuelson here, which has been a standard practice in the literature on tax and tariff policy reform (see, for example, Hatta, 1977; Dixit and Norman, 1980; Anderson, 1999). 
Given the assumption that the equilibrium is stable, the sign of welfare change $\mathrm{d} U /$ $\mathrm{d} \tau_{k}$ is determined by the signs of the right-hand side of Eq. (6) along with the sign of $\Psi_{k}$. A welfare worsening (improving) reduction in trade taxes is implied by $\mathrm{d} U / \mathrm{d} \tau_{k}>0(<0)$ if $k$ is an importable and by $\mathrm{d} U / \mathrm{d} \tau_{k}<0 \quad(>0)$ if it is an exportable. So the necessary and sufficient condition for a welfare reduction (improvement) is that the right-hand side of Eq. (6) is positive (negative). Observe that the expressions involved in the right-hand side of Eq. (6) are the compensated marginal costs of public funds (henceforth CMCF) of the two taxes under consideration (see Anderson, 2002).

The economic effects of a reform of an import tariff are very much different from that of a reform of an export tax. A reduction in an import tariff implies that the subsidy to domestic producers decreases $\left(p_{k} \downarrow\right)$ and the consumers benefit as the consumer price goes down $\left(q_{k} \downarrow\right)$. A reduction in an export tax, on the other hand, reduces subsidy on consumption $\left(q_{k} \uparrow\right)$, but increases domestic production as the producer price goes up $\left(p_{k} \uparrow\right)$. This implies that while a coordinated reform of VAT and import tariff has conflicting effects on consumer prices $\left(q_{k} \downarrow q_{i} \uparrow\right)$, a similar reform of VAT and export tax affects consumer prices in the same direction $\left(q_{k} \uparrow\right.$ $\left.q_{i} \uparrow\right)$. Given this fundamental difference, the results differ significantly. So these two cases are treated separately. In what follows, we first look at the case of an import tariff reform.

\section{Reducing import tariff with an increase in VAT}

In this section, we analyze the case of an import tariff reform accompanied by a revenue-neutral increase in VAT. From Eq. (6), a reduction in the import tariff on commodity $k$ with a concomitant revenue-neutral increase in the VAT on commodity $i$ will be welfare worsening (enhancing) if and only if the following holds:

$$
\frac{\mathrm{d} U}{\mathrm{~d} \tau_{k}}>0(<0) \Leftrightarrow E_{q_{i}^{f}} \Psi_{i}^{-1}>(<)\left(E_{q_{k}}-G_{p_{k}}\right) \Psi_{k}^{-1}
$$

What Eq. (7) says is completely intuitive: a reduction in the tariff on $k$, $\tau_{k}$, with a revenue-neutral increase in the VAT on $i, v_{i}$, is welfare worsening if and only if the CMCF of tariff on $k$ is lower than that of VAT on $i$. The more important question though is under what conditions Eq. (7) is likely to be satisfied. We turn to that question in the following.

We first analyze the simplest case where all cross-price effects are assumed to be zero. This can be thought of as an approximation of the case when the cross substitution effects are negligible relative to the own substitution effects. The basic results, presented below in proposition (1), can be viewed as extensions of the inverse elasticity rule of optimal taxation in an open economy to the case of revenue-neutral tax and tariff reform (see Dasgupta and Stiglitz, 1974). Since in this section we assume that commodity $k$ is an importable, we have $\tau_{k}>0$ and $\left(E_{q_{k}}-G_{p_{k}}\right)>0$. 


\section{Proposition 1.}

(a) Assume that the cross price effects are zero and that there is a positive tax burden on consumption of commodity $i$ at the initial position. Then, there exists a critical threshold such that if the VAT base of commodity $i$ is smaller than the threshold, the marginal revenue-neutral reform of import tariff $\left(\tau_{k}\right)$ and VAT $\left(v_{i}\right)$ reduces welfare. The threshold is lower, and thus a welfare-worsening reform is less likely, if commodity $k$ belongs to the formal sector.

(b) Assume that the cross price effects are zero and that $k$ is an informal importable with a positive tariff at the initial position. Then, there exists a threshold tariff rate $\hat{\theta}_{k} \equiv \hat{\tau}_{k}$ / $1+\hat{\tau}_{k}$ such that $\forall \theta_{k}<\hat{\theta}_{k}$, a further reduction in the tariff on $k$ with revenue-neutral increase in VAT on $i$ is welfare-worsening.

Proof. Proof of Proposition 1a.

From Eq. (6), the necessary and sufficient condition for a reduction in welfare can be written as follows:

$$
E_{q_{i}^{f}}<\hat{E}_{q_{i}^{f}} \equiv \begin{cases}\left(E_{q_{k}}-G_{p_{k}}\right)\left\{\frac{\left(v_{i}+\tau_{i}^{f}\right) E_{q_{i}^{f} q_{i}^{f}}}{v_{k} E_{q_{k} q_{k}}+\tau_{k}\left(E_{q_{k} q_{k}}-G_{p_{k} p_{k}}\right)}\right\}, & k \in f \\ \left(E_{q_{k}}-G_{p_{k}}\right)\left\{\frac{\left(v_{i}+\tau_{i}^{f}\right) E_{q_{i} q_{i}^{f}}}{\tau_{k}\left(E_{q_{k} q_{k}}-G_{p_{k} p_{k}}\right)}\right\}, & k \in \mathrm{S}\end{cases}
$$

Observe that $\hat{E}_{q_{i}^{f}}>0$ under the conditions stated in Proposition 1a. We have $\left(v_{i}+\tau_{i}^{f}\right)>0$ under the assumption that consumption of $i$ bears a positive tax burden, and $v_{k}, \tau_{k}>0$, given the assumption that there are no direct subsidies. ${ }^{17}$ The last part of Proposition 1a follows from observing that the threshold VAT base $\hat{E}_{q_{i}^{f}}$ below which the standard reform reduces welfare is, ceteris paribus, lower when commodity $k$ is produced in the formal sector, as long as the VAT on it is positive at the initial position, i.e., $v_{k}>0$. Even when the ceteris paribus assumption is relaxed, the conclusion is likely to be valid, as the consumption level when $k \in f$ and $v_{k}>0$ is necessarily lower due to a higher consumer price. However, the result is unambiguously valid in this case, only if the strength of own substitution effects $E_{q_{k} q_{k}}$ do not decrease at lower levels of consumption. $^{18}$

The above result relies on the classic observation that it is costly to raise tax revenue from a tiny base. The importance of this in the context of VAT in developing countries is that given the informational and administrative difficulties, the VAT base is usually very small, concentrated on a few large firms operating in the formal sector. The intuition behind Proposition 1a is as follows. A reduction in $\tau_{k}$ reduces the consumer price $q_{k}$ and

\footnotetext{
${ }^{17}$ Note that commodity $i$ necessarily bears a positive tax burden on consumption if it is an importable, given that we preclude any direct subsidies.

18 We thank an anonymous referee for pointing to us the implications of relaxing the ceteris paribus assumption.
} 
thus increases the domestic consumption of commodity $k$. If $k$ belongs to the formal sector, the increased consumption increases government revenue through existing VAT, $v_{k}$. But when it is in the informal sector, there is no extra VAT revenue from the increased consumption of $k$ because by definition it escapes the VAT net. A simple corollary of the above result is that, if at the initial position, the VAT is zero on commodity $k$, then it is immaterial whether the commodity is produced in the formal or informal sector. Observe that the last part of Proposition 1a regarding the sectoral identity of commodity $k$ remains equally valid, when there are non-zero cross price effects.

Proof. Proof of Proposition $1 b$.

When $k \in m s$, we have $v_{k}=0$ and $q_{k}=p_{k}$. In this case, the necessary and sufficient condition for a welfare worsening reform is given by the following inequality:

$$
\frac{\tau_{k}}{1+\tau_{k}}<\hat{\theta}_{k} \equiv \frac{\left(v_{i}+\tau_{i}^{f}\right)}{1+\left(v_{i}+\tau_{i}^{f}\right)} \frac{\lambda_{i}}{\mu k}
$$

where $\lambda_{i} \equiv E_{q_{i}^{f} q_{i}^{f}}\left(q_{i}^{f} / E_{q_{i}^{f}}\right)$ is the price elasticity of demand for commodity $i$ and $\mu_{k} \equiv\left(E_{q_{k} q_{k}}-G_{p_{k} p_{k}}\right)\left(q_{k} /\left(E_{q_{k}}-G_{p_{k}}\right)\right)$ is the price elasticity of import demand for commodity $k$. Observe that the right-hand side of inequality (9) is positive because $\lambda_{i}, \mu_{k}<0$. So if the tax rate (ad valorem) on $k$ is small enough the reform reduces welfare.

\section{The general case: non-zero cross substitution effects}

We now turn to the general case where the cross price effects are not zero, and present an analysis of the revenue-neutral selective reform of tax and tariff in an economy with and without an informal segment in the economy. We start with the case when there is no informal segment of the economy and establish sufficient conditions for a welfare enhancing reform, similar to, but slightly weaker than, the ones previously derived by Michael et al. (1993). We then turn to the central case: the revenue-neutral tax and tariff reform in an economy consisting of both formal and informal sectors. In Proposition 3, we show that, even with a strong assumption like universal pair-wise substitutability, there are plausible (sufficient) conditions under which the standard coordinated reform of tariff and VAT reduces welfare when there is an informal economy. This result raises serious doubts about the wisdom of the widely implemented indirect tax reform under the IMF and World Bank's policy conditionalities that puts strong emphasis on the supposed superiority of VAT over trade taxes on efficiency grounds, and embraces the goal of eliminating the trade taxes as an instrument of revenue raising. ${ }^{19}$ Before presenting the results, we state the following definitions.

\footnotetext{
${ }^{19}$ For example, the Tax Policy Handbook of IMF states the following: "While administrative costs of collecting trade taxes are low, the economic social cost of increasing trade taxes is generally higher than that of raising domestic taxes" (p. 201).
} 
Definitions. (a) Consider a set of commodities $D \subseteq T$ with $j \in D$. Commodity $j$ is called a substitute in consumption of the compound commodity $D_{-j}$ consisting of all other commodities in set $D$ except $j$, if the following holds:

$$
\sum_{r \in D, r \neq j}\left|\left(\beta_{r}-\beta_{j}\right)\right| E_{q_{j} q r}>0 .
$$

where $\beta$ 's, as defined earlier, denote the total tax burdens (VAT plus trade tax) on consumption of respective commodities. For example, $\beta_{r} \equiv v_{r}+\tau_{r}$ is the total indirect tax burden on consumption of commodity $r$.

(b) Consider a set of commodities $D \subseteq T$ with $j \in D$. Commodity $j$ is called a substitute of the compound commodity $D_{-j}$ in production, if the following holds:

$$
\sum_{r \in D, r \neq j}\left|\left(\tau_{r}-\tau_{j}\right)\right| G_{q_{j} q_{r}}<0
$$

Note that pair-wise substitutability in consumption and production are sufficient for compound substitutability, but not vice versa. This also implies that compound substitutability with respect to $D_{-j}$ does not imply compound substitutability with respect to any proper subset of $D_{-j}$.

The above definitions are due to Hatta (1986). We extend the definitions in the following way. If the inequalities in above definitions are weak rather than strict, then we call it weak compound substitutability. Also, when any given commodity is a pair-wise substitute of all other commodities in the economy, both in consumption and production, i.e., $E_{q_{j} q_{r}}>0, G_{q_{j} q_{r}}<0 \forall j \in T$ and $r \neq j$, then the commodity $r$ is called a universal pair-wise substitute. $^{20}$

Proposition 2. (Welfare-improving reform of tariff and VAT).

(a) In an economy with no informal segment, it is welfare enhancing to reduce the import tariff $\tau_{k}$ with a revenue-offsetting increase in the VAT $v_{i}$, if the following sufficient conditions hold:

(i) commodity $k$ is a weak substitute of the compound commodity consisting of all other commodities except $k, T_{-k}$, both in consumption and production;

(ii) commodity $i$ is a substitute of compound commodity consisting of all other commodities except $i, T_{-i}$, in consumption;

(iii) commodity $k$ bears the highest total indirect tax burden (VAT plus tariff) and also has the highest tariff, and commodity i bears the lowest total indirect tax burden.

(b) In an economy consisting of both formal and informal sectors, the conditions stated in Proposition 2a, if feasible, remain sufficient for a welfare improvement.

20 Throughout this paper, we use the assumptions of compound substitutability when analyzing the standard case, i.e., an economy with no informal sector. This helps to compare and contrast our results with the extant literature. While the compound substitutability assumptions are weaker in the sense that they allow for pair-wise complementarity, their dependence on the initial tax structure makes them less attractive on theoretical grounds. However, the results stated in terms of compound substitutability remain valid under the assumption of pair-wise substitutability, because the latter implies the former, but not vice versa. We use the assumptions of pair-wise substitutability which are independent of the tax structure for the central results of the paper dealing with an economy consisting of both formal and informal sectors. 
Proof. When there are non-zero cross price effects, from inequality (7), a welfareenhancing reform in an economy consisting of both formal and informal sectors requires that the following inequality is satisfied:

$$
E_{q_{i}^{f}}\left[\left(v+\tau^{f}\right)^{\prime} E_{q^{f} q_{k}}+\tau^{\mathrm{s}^{\prime}} E_{q^{s} q_{k}}-\tau^{\prime} G_{p p_{k}}\right]-\left(E_{q_{k}}-G_{p_{k}}\right)\left[\left(v+\tau^{f}\right)^{\prime} E_{q^{f} q_{i}^{f}}+\tau^{\mathrm{s}^{\prime}} E_{q^{s} q_{i}^{f}}\right]<0
$$

Now using the homogeneity properties of $E_{q_{j}}$ and $G_{p_{j}}$, inequality (12) can be rewritten as follows (for details, see Emran and Stiglitz, 2002, pp. 36-37):

$$
\begin{aligned}
E_{q_{i}^{f}} & {\left[\frac{1}{q_{k}} \sum_{j \neq k, j \in f}\left(\beta_{j}-\beta_{k}\right) E_{q_{k} q_{j}^{f}}-\sum_{j \neq k} \frac{\left(\tau_{j}-\tau_{k}\right)}{p_{k}} G_{p_{k} p_{j}}\right]-\left(E_{q_{k}}-G_{p_{k}}\right) } \\
\times & {\left[\sum_{j \neq i, j \in f} \frac{\left(\beta_{j}-\beta_{i}^{f}\right)}{q_{i}^{f}} E_{q_{i}^{f} q_{j}}\right]+\left(E_{q_{k}}-G_{p_{k}}\right)\left[\frac{1}{q_{i}^{f}} \sum_{j \in s}\left(\beta_{i}^{f}-\tau_{j}\right) E_{q_{i}^{f} q_{j}}\right] } \\
& +E_{q_{i}^{f}}\left[\frac{1}{q_{k}} \sum_{j \in s}\left(\tau_{j}-\beta_{k}\right) E_{q_{k}} q_{j}\right]<0
\end{aligned}
$$

So a reduction in $\tau_{k}$ with a revenue-neutral increase in $v_{i}$ will be welfare enhancing if and only if inequality (13) is satisfied. This inequality is the key to Proposition 2.

If there is no informal sector, as in Proposition 2a, then inequality (13) simplifies to the following:

$$
\begin{aligned}
& E_{q_{i}} {\left[\frac{1}{q_{k}} \sum_{j \neq k, j \in f}\left(\beta_{j}-\beta_{k}\right) E_{q_{k} q_{j}}-\frac{1}{p_{k}} \sum_{j \neq k, j \in f}\left(\tau_{j}-\tau_{k}\right) G_{p_{k} p_{j}}\right]-\left(E_{q_{k}}-G_{p_{k}}\right) } \\
& \times\left[\frac{1}{q_{i}} \sum_{j \neq i, j \in f}\left(\beta_{j}-\beta_{i}^{f}\right) E_{q_{i} q_{j}}\right]<0
\end{aligned}
$$

A set of sufficient conditions that satisfy inequality (14) are as follows: (i) $\beta_{k}>\beta_{j}$, $\forall j \neq k$; (ii) $\beta_{i}^{f}<\beta_{j}, \forall j \neq i$; (iii) $\tau_{k}>\tau_{j}, \forall j \neq k$; (iv) $k$ is a weak substitute of the compound commodity $T^{-k}$ both in consumption and production, and $i$ is a substitute of compound commodity $T^{-i}$ in consumption. These are the conditions stated in Proposition 2a above. Now, observe that, if there is an informal segment of the economy, Eq. (13) can still be collapsed to Eq. (14) with $j \in T$, instead of $j \in f$, given that the indirect tax burden on consumption of an informal commodity is, by definition, equal to the trade tax, i.e., $\tau_{j} \equiv \beta_{j}$, $\forall j \in \mathrm{s}$.

Sufficient conditions similar to Proposition 2a were earlier derived by Michael et al. (1993), which are, however, over-sufficient as they do not allow for weak compound substitutability. ${ }^{21}$

The above analysis shows that, formally, the same conditions remain sufficient for a welfare improvement, even when the economy consists of both formal and informal

\footnotetext{
21 In addition, Michael et al. require that the marginal revenue effects of both the taxes need to be positive, as we assume throughout this paper.
} 
sectors. One might be tempted to interpret this as an indication of the robustness of the results. However, the existence of an informal sector compromises the plausibility of these conditions in a very fundamental way. It is almost impossible to satisfy the condition that commodity $i$ bears the lowest indirect tax burden on consumption in the presence of a large informal sector, as is the case in developing countries. This is due to the fact that $i$ is necessarily a formal commodity given the assumption that a VAT can be collected on it. In general, the total indirect tax burden on a formal commodity is higher than that on an informal commodity because of VAT. The exportables produced in the informal sector are likely to bear non-positive indirect tax burden because a VAT cannot be imposed on them and export tax subsidizes their consumption. Thus the informal exportables are the most likely candidates to bear the lowest indirect tax burden. ${ }^{22}$ More important, when there are direct subsidies, as is the case in most of the developing countries, any arbitrary informal commodity can enjoy the distinction of the lowest indirect tax burden. This severely restricts the applicability of Proposition 2. While in an economy without an informal segment, the commodity with lowest indirect tax burden is, by definition, under VAT coverage, there is no guarantee that a VAT can be levied on the commodity bearing the lowest indirect tax burden when there is a subset of commodities that escapes the VAT net. ${ }^{23}$ In this case, the best one can do is to look for the commodity with the lowest indirect tax burden among the subset of formal commodities as the candidate for VAT increase. This restriction on the choice of the candidate commodity for VAT increase, while relevant even for developed countries, assumes a critical dimension in developing countries where more than half of the GDP originates in the informal economy. As we show in what follows, in this more realistic case, the standard revenue-neutral selective reform of import tariff and VAT reduces welfare under plausible (sufficient) conditions, even under a stronger substitutability assumption like universal pair-wise substitutability.

Proposition 3. (Welfare-reducing reform of tariff and VAT with an informal economy). In an economy with both formal and informal sectors, assume that

(a) $k$ is a universal pair-wise substitute and $i$ is a pair-wise substitute of all other commodities in consumption;

(b) commodity $k$ bears the highest indirect tax burden on consumption and also the highest tariff among all commodities;

(c) commodity $i$ enjoys the lowest indirect tax burden among the subset of formal commodities.

Then, a marginal reduction in tariff on $k$ with a revenue-neutral increase in VAT on $i$ reduces welfare if (i) the indirect tax burden on consumption of $i$ is higher than a (possibly negative) threshold and (ii) the VAT base for commodity $i$ is smaller than a positive threshold.

\footnotetext{
22 The agricultural exports produced by numerous dispersed small farmers fit into this category.

23 Note that commodity $k$ can belong to either formal or informal sector, because a VAT need not be levied on
} it. 
Proof. The necessary and sufficient condition for a welfare reduction following a marginal decrease in $\tau_{k}$ with a revenue-neutral increase in $v_{i}$ is given by the following inequality:

$$
\begin{aligned}
& E_{q_{i}^{f}}<\tilde{E}_{q_{i}^{f}} \equiv\left(E_{q_{k}}-G_{p_{k}}\right) \frac{\Delta_{i}}{\Delta_{k}} \\
& \text { where } \Delta_{i} \equiv\left[\frac{1}{q_{i}^{f}} \sum_{j \neq i}\left(\beta_{j}-\beta_{i}^{f}\right) E_{q_{i}^{f} q_{j}}\right] \\
& \Delta_{k} \equiv\left[\frac{1}{q_{k}} \sum_{j \neq k}\left(\beta_{j}-\beta_{k}\right) E_{q_{k} q_{j}}-\frac{1}{p_{k}} \sum_{j \neq k}\left(\tau_{j}-\tau_{k}\right) G_{p_{k} p_{j}}\right]<0
\end{aligned}
$$

Inequality (17) above follows from the assumptions of universal pair-wise substitutability and the highest tax and tariff assumptions for commodity $k$. It is obvious that, under the assumption of pair-wise substitutability in consumption, $\sum_{j \neq i} E_{q_{i}^{f} q_{j}}>0$. It immediately follows that $\Delta_{i}<0$, if $\beta_{i}^{f}$ is high enough to satisfy the following ${ }^{24}$ :

$$
\beta_{i}^{f}>\tilde{\beta}_{i}^{f} \equiv \frac{\sum_{j \neq i} \beta_{j} E_{q_{i}^{f} q_{j}}}{\sum_{j \neq i} E_{q_{i}^{f} q_{j}}}
$$

So if $\beta_{i}^{\mathrm{f}}>\tilde{\beta}_{i}^{f}$, we have $\Delta_{i}<0$, which, in turn, implies that $\tilde{\mathrm{E}}_{q_{i}^{f}}>0$. In this case, if the domestic consumption of $i$ (VAT base) is sufficiently low to satisfy inequality (15), the standard revenue-neutral tariff and VAT reform reduces welfare.

Note that, given an indirect tax structure, the value of $\sum_{j \neq I} \beta_{j} E_{q_{i}^{f} q_{j}}$ is lower when commodity $i$ is a strong substitute ${ }^{25}$ of the commodities with a net subsidy on consumption. Under the assumption that there are no direct subsidies, only the exportables can enjoy subsidies on consumption. Especially $\beta_{j}<0, \forall j \in x s$, i.e., the consumption of informal exportables is subsidized irrespective of the VAT structure, as long as there are export taxes. So $\sum_{j \neq i} \beta_{j} E_{q_{i}^{f} q_{j}}$ and hence $\tilde{\beta}_{i}^{f}$ will be low or even negative, if commodity $i$ is a strong substitute of informal exportables in consumption, but the substitutability with respect to the commodities with a positive tax burden on consumption is not strong enough. When direct subsidies are allowed, the consumption of any arbitrary commodity can be subsidized at the initial position, and one can have a negative $\tilde{\beta}_{i}^{f}$ even if commodity $i$ is not a strong substitute of informal exportables in consumption. It is also important to note that the threshold VAT base below which the standard reform reduces welfare is, ceteris paribus, higher the higher is the value of imports of commodity $k$ at world price

${ }^{24}$ Observe that $\beta_{i}^{f}$ can be positive and still satisfy the requirement that commodity $i$ bears the lowest indirect tax burden on consumption among all formal commodities, given that the numeraire commodity which has a zero tax burden by definition is assumed to belong to the informal economy.

25 Here the term strong "substitute" is used to denote the strength of substitutability only and is not related to the definition due to Hatta and Haltiwanger (1986). 
$\left(E_{q_{k}}-G_{p_{k}}\right)$. So it is more likely to have a welfare reduction when import tariff reform involves a commodity that has a significant weight in the consumption but a small domestic production.

We now turn to a straightforward but important corollary of Proposition 3 above. One of the central features of the indirect tax reform in developing countries has been the emphasis on the desirability of base broadening of VAT. But inequality (18) above can be satisfied even when commodity $i$ bears no tariff or VAT at the initial position. This implies from Eq. (15) that, if the potential VAT base for commodity $i$ is smaller than a threshold, a VAT base broadening to include commodity $i$ with a revenue-neutral cut in import tariff on another commodity will reduce welfare. As we noted in the introduction, a welfare-worsening base broadening of VAT is not just a theoretical possibility; its empirical relevance has recently been demonstrated by Piggott and Whalley (2001) in the context of GST in Canada. If a VAT base broadening is likely to be welfareworsening in a country like Canada where the size of the shadow economy is only about one fourth of the average size of the shadow economy in developing countries, it is a fair conjecture that such a reform will, a fortiori, be welfare-reducing in developing countries. ${ }^{26}$ The following corollary states the conditions for a welfarereducing base broadening of VAT when the revenue-neutrality is preserved by cutting import tariff on another commodity.

Corollary 3.1. (Welfare-reducing base broadening of VAT). Assume that $v_{i}=\tau_{i}^{f}=0$ and $\tilde{\beta}_{i}^{f}<0$ at the initial position, and that conditions (a)-(c) ofProposition 3 are satisfied. Then, a tax reform that reduces the tariff on commodity $k$ and balances the budget by broadening the VAT base to bring commodity $i$ under the tax net, reduces welfare if the VAT base of $i$ is smaller than a (positive) threshold.

Note that, if the tariff on commodity $i$ is positive, but there is no VAT at the initial position, then the introduction of VAT on commodity $i$ will reduce welfare as long as $\tau_{i}^{f}>\tilde{\beta}_{i}^{f}$, even if $\tilde{\beta}_{i}^{f}>0$.

\section{Reducing export tax with an increase in VAT}

This section is devoted to an analysis of the case where commodity $k$ is an exportable implying that $\tau_{k}<0$ and $\left(E_{q_{k}}-G_{p_{k}}\right)<0$. We explore sufficient conditions for a welfareworsening or welfare-improving reduction in the export tax, $-\tau_{k}$, with a concomitant revenue-neutral increase in VAT on commodity $i, v_{i}$. As in the previous section dealing with the case of import tariff, we begin our analysis with the simple case where all cross price effects are assumed to be zero. An interesting result that contrasts with the case of an import tariff reform (see Proposition 1) is that a reduction in the export tax is more likely to be welfare worsening when it is produced in the formal sector. Proposition 4 below states the results.

\footnotetext{
26 The estimate of shadow economy in Canada used by Piggott and Whalley is 10\% of GDP. Recall that the average size of shadow economy is 39\% for 1989-1993 according to the estimates of Schneider and Enste (2000).
} 


\section{Proposition 4.}

(a) Assume that there are no cross price effects and that the consumption of commodity $i$ bears a positive tax at the initial position. Then, a reduction in $-\tau_{k}$ with a revenueneutral increase in $v_{i}$ leads to a reduction in welfare if the VAT base is sufficiently small to begin with. It is, ceteris paribus, more likely to have a welfare-worsening reform when commodity $k$ belongs to the formal sector.

(b) Assume that there are no cross price effects, and the consumption of $i \in T$ and $k \in x f$ bears positive tax at the initial position. Then, a reduction in $-\tau_{k}$ with a revenueneutral increase in $v_{i}$ leads to a reduction in welfare irrespective of the relative size of the tax bases, if the initial export tax is sufficiently low.

Proof. Proof of Proposition 4a.

When all cross price effects are zero and $k \in x$, from Eq. (6), the necessary and sufficient condition for an welfare reduction is given by the following inequality:

$$
\left(G_{p_{k}}-E_{q_{k}}\right)> \begin{cases}E_{q_{i}^{f}}\left\{\frac{-\left(v_{k}+\tau_{k}\right) E_{q_{k} q_{k}}+\tau_{k} G_{p_{k} p_{k}}}{\left(v_{i}+\tau_{i}^{f}\right) E_{q_{i}^{f} q_{i}^{f}}}\right\}, & k \in f \\ E_{q_{i}^{f}}\left\{\frac{\tau_{k}\left(G_{p_{k} p_{k}}-E_{q_{k} q_{k}}\right)}{\left(v_{i}+\tau_{i}^{f}\right) E_{q_{i}^{f} q_{i}^{f}}}\right\}, & k \in S\end{cases}
$$

The proof follows immediately by observing that, under the conditions stated in Proposition $4 \mathrm{a}$, the inequality above is satisfied, if $E_{q_{i}}^{f}$ is sufficiently small. The implications of the sectoral identity of commodity $k$ is similar to that discussed for Proposition 1a (for details, see Emran and Stiglitz, 2002, p. 23).

The intuition for this result is again simple and mirrors the result on the implications of the sectoral identity of an importable commodity discussed in Proposition 1, and thus is omitted for the sake of brevity. The policy implication of the above result is that a reduction in export tax on the large scale manufacturing exports, and agricultural exports produced in plantations needs more careful scrutiny because of the possible loss in VAT revenue.

Proof of Proposition 4b.

The sign of the right-hand side of inequality (19) for the case $k \in f$ depends on the sign of the numerator which can be either positive or negative. It can be easily verified that the numerator is positive if the following holds (given that the consumption of $k$ bears a positive tax):

$$
-E_{q_{k} q_{k}}>\left(\frac{-\tau_{k}}{v_{k}+\tau_{k}}\right) G_{p_{k} p_{k}}
$$


Now observe that $\lim _{\tau_{k}}\left(\frac{-\tau_{k}}{v_{k}+\tau_{k}}\right)=0$. So given any nonzero and finite consumption and production substitution effects, there always exists a small enough export tax $-\tau_{k}>0$ such that inequality (20) is satisfied. In this case, the right-hand side of inequality (19) for $k \in f$ is negative, and the inequality is satisfied irrespective of the relative size of the tax bases, and hence the standard marginal reform of VAT and export tax reduces welfare.

\section{The general case: non-zero cross substitution effects}

We now turn to the general case with non-zero cross substitution effects. An important result here is that, even without an informal sector, the sufficient conditions needed to secure a welfare improvement are much more stringent and ad hoc in this case when compared to the case of a reduction in an import tariff, as discussed in Proposition 2. Unlike the case of an import tariff reform, a reduction in export tax on $k$ with a concomitant revenue-neutral increase in VAT on $i$ can be welfare reducing in an economy consisting of only formal sector under the assumption of substitutability. In what follows, Propositions 5 and 6 report the results for the case where the economy consists entirely of formal sector so that any arbitrary commodity can be chosen as the candidate for VAT increase. This is followed by the results on the central case with both formal and informal sectors so that the search for the candidate for VAT increase is limited within the formal sector.

Proposition 5. (Welfare-improving reform of VAT and export tax without an informal economy).

In an economy without any informal segment, there, in general, does not exist compound substitutability assumptions that can ensure a welfare-improvement from a marginal reduction in export tax on $k$ with revenue-neutral adjustments in VAT on $i$. A set of sufficient conditions for such a revenue-neutral marginal tax reform to be welfareimproving is as follows:

(i) commodity $k$ enjoys the lowest and commodity $i$ the second lowest indirect tax burden on consumption among all commodities;

(ii) commodity $k$ bears the highest export tax;

(iii) commodity $k$ is a weak substitute, both in consumption and production, of the compound commodity $T_{-k}$, and $i$ a weak substitute of the compound commodity, $T_{-k, i}$ in consumption;

(iv) $k$ and $i$ are pair-wise complements in consumption.

Proof. When the export tax on $k$ is reduced with a concomitant increase in VAT on $i$ so that total revenue remains the same, the following inequality provides us with the necessary and sufficient condition for a welfare improvement:

$$
E_{q_{i}^{f}} Z_{1}+\left(G_{p_{k}}-E_{q_{k}}\right) Z_{2}+Z_{3}>0
$$


where

$$
\begin{aligned}
& Z_{1}=\frac{1}{q_{k}} \sum_{j \neq k}\left(\beta_{j}-\beta_{k}\right) E_{q_{k} q_{j}}-\frac{1}{p_{k}} \sum_{j k}\left(\tau_{j}-\tau_{k}\right) G_{p_{k} p_{j}} \\
& Z_{2}=\frac{1}{q_{i}^{f}} \sum_{j \neq i, k}\left(\beta_{j}-\beta_{i}^{f}\right) E_{q_{i}^{f} q_{j}} \\
& Z_{3}=\left(G_{p_{k}}-E_{q_{k}}\right) E_{q_{i}^{f} q_{k}}\left[\frac{\beta_{k}-\beta_{i}^{f}}{q_{i}^{f}}\right]
\end{aligned}
$$

Now note that $\left(\beta_{j}-\beta_{k}\right)>0, \forall j \neq k$ under the assumption that commodity $k$ enjoys the lowest indirect tax burden. The fact that $k$ bears the highest export tax implies $\left(\tau_{j}-\tau_{k}\right)>0$ $\forall j \neq k$. Also, $\left(\beta_{j}-\beta_{i}^{f}\right)>0, \forall j \neq i, k$ because $i$ enjoys the second lowest consumption tax burden. These, coupled with the assumptions of weak compound substitutability in consumption and production, ensure that $Z_{1}, Z_{2} \geq 0$. Now $\left(\beta_{j}-\beta_{k}\right)>0, \forall j \neq k$ implies, in particular, that $\left(\beta_{k}-\beta_{i}^{f}\right)<0$, which in turn implies that $Z_{3}$ is positive, when $k$ and $i$ are pairwise complements in consumption, as assumed in Proposition 5. This completes the proof of Proposition 5. ${ }^{27}$

Observe the difference in the choice of appropriate $k$ and $i$ above compared to the case of an import tariff reform, as discussed in Proposition 2. In case of an import tariff reform, we need to squeeze the two polar tax rates from upper and lower tails of the indirect tax structure. In contrast, here, we need to pick both $k$ and $i$ from the lower end of the indirect tax structure. This difference reflects the fact that these two cases have different implications for consumer prices. The effect on the consumer price of a reduction in the import tariff is opposite to that of an increase in VAT; a lower import tariff means a lower consumer price, while a higher VAT implies a higher consumer price. In case of export tax reform, the effects work in the same direction; both a reduction in export tax and a higher VAT increase consumer price. Since, in this case, the tax changes increase consumer prices of both $k$ and $i$, the consumer substitutes away from both of these commodities. Such substitution effects are likely to have positive revenue implications only when all other commodities bear higher indirect taxes at the initial position, compared to both $k$ and $i$.

One unattractive feature of Proposition 5 is that, in general, it is very difficult, if not impossible, to find a pair of commodities, $k$ and $i$, which simultaneously satisfy the complementarity condition, and the lowest and second lowest tax burdens assumption. This significantly restricts the applicability of such a reform strategy. However, if we abandon the complementarity condition, a welfare-worsening outcome is possible when

\footnotetext{
27 The sufficient conditions for a welfare improvement when $i$ enjoys the lowest and $k$ the second lowest indirect tax burden on consumption are similar to the ones derived here, as long as complementarity between $k$ and $i$ in consumption is assumed.
} 
the revenue-neutral marginal VAT and export tax reform is implemented. Proposition 6 below provides a set of sufficient conditions for such a welfare-reducing reform.

Proposition 6. (Welfare-reducing reform of VAT and export tax without an informal economy).

Assume that

(i) commodity $k$ is a weak substitute, both in consumption and production, and $i$ a weak substitute in consumption of the compound commodity $T_{-k, i}$;

(ii) $k$ and $i$ are pair-wise substitutes in consumption;

(iii) the domestic consumption of $i$ (VAT base) is low enough, and the exports of $k$ high enough, so that the consumer expenditure on $i$ is lower than the value of exports of $k$ at domestic consumer price.

Then, a reduction in the export tax on $k$ with a revenue-neutral adjustment in VAT on $i$ is welfare worsening if the cross substitution effect between $k$ and $i$ is sufficiently strong.

Proof. Omitted. See Emran and Stiglitz (2002, p. 28).

The important point to note about the above proposition is that when the pair of commodities under reform are close substitutes of each other but their cross substitutability with respect to all other commodities is low, then the standard reform is more likely to reduce welfare. Again, it is straightforward to show that a smaller VAT base for commodity $i$ makes it more likely that the reform will reduce welfare (see Emran and Stiglitz, 2002, pp. 28-29). As we already noted, since the VAT base is usually small in developing countries, it seems plausible that the conditions for Proposition 6 will be satisfied. Proposition 6(iii) implies that it is more likely to have a welfare reduction when the export tax reform targets the main export items in a country for which the value of exports in domestic consumer price will be high.

We now turn to the central case where the economy consists of both formal and informal segments and consequently the search for the candidate commodity for a VAT increase is limited within the formal sub-sector. The results, reported in Proposition 7 below, although closely correspond to the results for an import tariff reform reported in Proposition 3 above, there is an important difference, as explained in the discussion following the proposition.

Proposition 7. (Welfare-reducing reform of VAT and export tax with an informal economy).

In an economy with both formal and informal sectors, assume that

(a) $k$ is a universal pair-wise substitute and $i$ is a pair-wise substitute of all other commodities in consumption;

(b) commodity $k$ bears the lowest indirect tax burden on consumption among all commodities and also the highest export tax; and

(c) commodity $i$ bears the lowest indirect tax burden on consumption among the subset of formal commodities. 
Then, a marginal reduction in export tax on $k$ with revenue-neutral increase in VAT on $i$ is welfare-worsening if (i) the indirect tax burden on consumption of $i$ is higher than a (possibly negative) threshold and (ii) the VAT base for commodity $i$ is smaller than a positive threshold.

Proof. Omitted. See Emran and Stiglitz (2002, p. 30).

Although the basic insight underlying Proposition 7 above is similar to that for Proposition 3 discussed earlier, there is an important difference that deserves consideration here. Since it is assumed in Proposition 7 that the tax burden on consumption of $k$ is less than that on $i$, the conditions for welfare reducing outcome are likely to be rather easily satisfied when $k$ and $i$ are close substitutes in consumption, especially if the substitution elasticities between $i$ and all other commodities (except $k$ ) are low. This is in sharp contrast to the case of an import tariff reform in Proposition 3, where the tax burden on $k$ is always higher than that on $i$. Consequently, in case of an import tariff reform, a higher substitutability between $k$ and $i$ makes it harder to satisfy inequality (19).

Corollary 7.1. (Welfare-worsening VAT base broadening and export tax reform). Now observe that Propositions 6 and 7 remain valid when at the initial position commodity $i$ is not under the tax net and total indirect tax burden on it is zero. ${ }^{28}$ This implies that a reduction in export tax on commodity $k$ with a revenue-neutral VAT base broadening to bring commodity $i$ under the VAT net will be welfare reducing if the conditions stated in Propositions 6 and 7 are satisfied.

\section{Concluding remarks}

In this paper, we have presented an analysis of selective reform of trade taxes and VATs in developing countries that takes into account the implications of a large informal sector in the economy. The results are, in general, sobering, and they raise serious doubts about the validity of the current consensus that favors a reduction and eventual elimination of trade taxes, and almost exclusively relies on VAT as the instrument of indirect taxation in developing countries. The results on a coordinated reform of import tariff and VAT show that, the incomplete coverage of VAT due to the existence of a large informal sector renders the results derived earlier in the literature unhelpful at best and potentially misleading as the basis of indirect tax policy reform in developing countries. When the choice of the commodity for VAT increase is restricted by the existence of a large informal sector, the standard policy reform can reduce welfare under plausible (sufficient) conditions. A revenue-neutral selective reform of export tax and VAT requires extremely stringent assumptions to secure a welfare improvement, and may reduce welfare, even in the absence of an informal segment in the economy. These conclusions run counter to the

\footnotetext{
${ }^{28}$ Note that, in this case, the assumption that $k$ bears the lowest indirect tax implies that the consumption of $k$ is subsidized at the initial position, i.e., $\beta_{k}<0$.
} 
conventional wisdom that VAT is a better instrument for raising revenue in developing countries compared to the trade taxes. A tax policy practitioner, at this point, might raise the following issue regarding the implications of the above theoretical results for the policy reform on the ground. Since a significant part of the VAT revenue in a typical developing country comes from the VAT collected at the border, it is essentially a trade tax in the guise of VAT, a point discussed earlier (see footnote 14). In this case, the tax reform policies implemented under the IMF and World Bank policy conditionalities are not as damaging. ${ }^{29}$ However, it is difficult to reconcile this argument with the view that trade taxes are inefficient as instruments of revenue raising and the tax reform policies implemented under the IMF and World Bank conditionalities are designed to improve efficiency in resource allocation by reducing the trade taxes and shifting the burden of revenue raising to the more efficient VAT. ${ }^{30}$ The goal of eliminating trade taxes implies that the part of VAT that is collected at the border should also be eliminated, especially when the corresponding domestic production can not be equally taxed under VAT due to its informal character.

The simple model used in this paper, albeit standard in the literature, ignores some important aspects of economic reality in developing countries. They include the existence of nontradables and intermediate goods, differential administrative costs of different taxes, smuggling and cross-border shopping. We briefly discuss the likely implications of these factors for the results presented in this paper.

First, the assumption that the economy consists only of tradables, although widely used, is obviously at variance with the economic reality in developing countries. However, when extended to include nontradables, it is likely to strengthen the conclusions of this paper. When all commodities are tradable, we can pick any arbitrary commodity as the candidate for trade tax reform. The existence of nontradables imply that the search for the appropriate commodity for reform of import tariff or export tax has to be restricted within the subset of tradable commodities. This may not be very restrictive in the context of an import tariff reform, as most of the nontradables (like public utilities) in developing countries are either untaxed or enjoy subsidies on consumption. Thus, it still seems to be a reasonable assumption that the commodity bearing the highest indirect tax will be an importable. The case for a coordinated reform of export tax and VAT, however, becomes even weaker in this case. In the presence of nontradables with subsidy on consumption, the assumption that the commodity with the lowest indirect tax burden is an exportable may not be satisfied. ${ }^{31}$

Second, an analysis of the implications of VAT revenue on intermediate inputs that remains unclaimed by informal firms is important. However, it raises a number of issues that deserve a separate treatment on its own (see Emran and Stiglitz, 2003a). We provide a brief discussion of some of the issues pertinent to the present context. Although there are well-known reasons to be cautious about taxing intermediate goods for revenue purpose

${ }^{29}$ We thank Mick Keen and Ravi Kanbur for raising this point.

${ }^{30}$ According to the recent IMF publication titled The Modern VAT (Ebrill et al., 2001): "..the case for the value-added tax rests upon the view that a well designed and implemented VAT is a particularly efficient tax" (p. 27).

31 In the context of radial uniform reform in the absence of an informal economy, Anderson (1999) and Keen and Ligthart (2002) show that it is much more difficult, if not impossible, to ensure a welfare improvement, when nontradables are accommodated in the model compared to the simpler case of a tradables-only economy. 
including production inefficiency and inefficient incentives for vertical integration, it might be desirable to tax the intermediate inputs of the informal sector firms as an indirect way of taxing them (Newbery, 1986). It seems especially promising in case of a VAT as the production efficiency is preserved within the formal sector and only the informal sector firms pay the input taxes as they are not able to claim the rebates. However, the existence of unclaimed rebates on VAT on intermediate goods by the informal firms may in fact strengthen our results when the exportable (importable) under reform is produced in the formal (informal) sector, while the converse cases require additional qualification(s). Let us consider the case where $k$ is an exportable produced in the formal sector. A reduction in export tax increases the producer prices of $k$ that pulls resources away from other sectors including the informal economy as the production of $k$ expands. This reduces the output and hence the demand for formal inputs by the informal economy and thus reduces the VAT revenue from intermediate inputs. So our results on the reform of export tax and VAT are strengthened when the VATs on intermediate inputs are taken into account. Next, consider the case where $k$ is an importable good produced in the informal economy. In this case, the net effect of a reduction in the tariff on $k$ on the demand for formal intermediate inputs by the informal sector is ambiguous, á priori. Because while the production of $k$ goes down, resources are reallocated to other informal commodities along with the formal sector. However, the net demand for formal intermediate inputs will decrease if either (i) most of the resources are reallocated to the formal sector, or (ii) commodity $k$ uses the formal intermediate inputs more intensively than the average (appropriately weighted) of the informal sector. This lowers VAT revenue from intermediate inputs and strengthens our result. Finally, consider the case of import tariff reduction when $k$ is a final commodity produced in the formal economy. The result is a reduction in the production of commodity $k$ as the tariff protection goes down, and a reallocation of resources to the other sectors of the economy. In so far as, this reallocation increases the production in the informal economy, it increases the demand for intermediate inputs, and thus increases the VAT revenue from formal intermediate inputs subject to VAT (unclaimed by the informal firms). However, if this indirect effect is small enough, our result still goes through. The indirect revenue effect of VAT on inputs is likely to be insignificant when (i) the VAT on inputs used intensively by the informal sector is low (or zero, as is the case for agricultural inputs in most of the developing countries) and (ii) the informal inputs markets are thick enough so that informal firms' demand for formal inputs is small.

Third, it is well-known that trade taxes enjoy a clear advantage over VAT on account of administrative costs (see, for example, World Development Report, 1988). In fact, administrative advantage has been the usual explanation for the pervasive use of trade taxes in early stages of development (Hinrichs, 1966; Musgrave, 1969). The informational and compliance costs of VAT are likely to be high, especially in developing countries, because of high rates of illiteracy and scant written record-keeping. ${ }^{32}$ As the firms in

32 The recent evidence from cross-country regressions show that, “..all else equal, the VAT yields less revenue in less literate economies" (Ebrill et al., 2001, p. 47). No formal estimate of the administrative and compliance costs of VAT in developing countries are available in the literature. The available estimates for developed countries can, however, be suggestive. The administration costs of a broadly "best practice" VAT is around $\$ 100$ per registrant per annum in OECD countries, while the corresponding figure for compliance cost is $\$ 500$ (Cnossen, 1994). For Singapore, the estimated compliance cost is $\$ 700$ (Jenkins and Khadka, 1997). 
developed countries usually keep records for monitoring and for other purposes unrelated to tax compliance, the marginal compliance costs of VAT are substantially lower. There are also evidence of a close link between the lack of record-keeping and tax evasion, as the detailed case study of Cameroon by Gauthier and Gersovitz (1993) shows.

Fourth, the issue of smuggling and its pernicious effects are largely country specific; it depends, among other things, on how porous the border is, and on the effectiveness of the border monitoring. It is, however, important to recognize that both the trade taxes and VAT can be vulnerable to smuggling. As noted elsewhere (Emran and Stiglitz, 2000b), an increase in the import taxes increases the returns to both domestic production and smuggling, so that the extent of smuggling is constrained by the higher domestic supply of a commodity. A higher VAT, on the other hand, increases the consumer price but leaves the returns to the domestic producers unchanged. This implies a higher return to smuggling relative to domestic production, assuming that the commodity in question is an importable. So one would expect an increase in smuggling as some of the import substituting entrepreneurs, along with others, turn into "smuggler entrepreneurs". Since domestic supply is reduced (or at least fixed), the extent of smuggling, in this case, is likely to be higher compared to the case of an import tax. In case of an increase in the VAT on an exportable commodity, there are no effects on domestic production and no incentives are generated for smuggling out of the country. This can be an important advantage in some African countries where significant smuggling resulted from very high export taxation. A reduction in export taxes also has desirable effects. It reduces smuggling and increases domestic production, and thus is likely to increase the volume of legal exports, and add to the export tax revenue.

The issue of cross-border shopping has recently gained prominence in the context of VAT (for a discussion, see Ebrill et al., 2001). In contrast to VAT, trade taxes do not encourage cross-border shopping, assuming that the customs administration is reasonably efficient.

The results on the selective reform of trade tax and VAT presented in this paper, and the ones on the radial reform presented recently by Emran and Stiglitz (2000a), together provide strong grounds for a re-evaluation of the indirect tax reform in developing countries. ${ }^{33}$

We are not aware of any empirical work that deals with the issues raised in this paper. The theoretical results presented here, however, suggest that the existing empirical estimates (for example, Clarete and Whalley, 1987; Anderson, 1996) of social costbenefit of trade taxes vis a vis VATs (consumption taxes) should be interpreted with due caution, as they do not pay adequate attention to the implications of an informal economy. ${ }^{34}$ New empirical work within CGE framework that explicitly incorporates the role of the informal economy will be invaluable in informing the tax policy reform in developing countries.

${ }^{33}$ See also the analysis of the consumer and producer price-neutral tax reform in Emran and Stiglitz (2003b) where we show that the reform schemes for reducing trade taxes advocated in recent literature (for example, Hatzipanayotou et al., 1994) also critically depend on the assumption that there is no informal sector in the economy.

${ }^{34}$ It is interesting to note that, even without an informal economy (which is likely to favor the VAT), the empirical results of Anderson (1996) show that a reduction in trade taxes with a revenue-neutral increase in VAT reduces welfare in case of Korea. 


\section{Acknowledgements}

We would like to thank Jean-Yeves Duclos, Umberto Galmarini, Ravi Kanbur, Mick Keen, Ronald Mckinnon, Dilip Mookherjee, Forhad Shilpi, Gavin Wright, two anonymous referees of this journal and the seminar participants in Stanford Trade and Development workshop, the Econometric Society Summer Meetings, 2001 at University of Maryland, the Cornell-ISPE conference on "Development and Public Finance", September 2001, NEUDC 2002 at Williams College, George Washington University and North South University, Bangladesh for useful comments on earlier versions.

\section{References}

Abe, K., 1995. The target rates of tariff and tax reform. International Economic Review 36, 875-885.

Anderson, J., 1996. Trade reform with a government budget constraint. NBER working paper 5827.

Anderson, J., 1999. Trade policy reform with a government budget constraint. In: Piggott, J., Woodland, A. (Eds.), International Trade Policy and the Pacific Rim. Macmillan, London.

Anderson, J., 2002. Trade reform diagnostics with many households, quotas and tariffs. Review of International Economics 10 (May).

Clarete, R.L., Whalley, J., 1987. Comparing the marginal welfare costs of commodity and trade taxes. Journal of Public Economics 33, 357-362.

Cnossen, S., 1994. Administrative and compliance costs of the VAT: a review of evidence. Tax Notes 63, $1609-1626$.

Dasgupta, P., Stiglitz, J., 1974. Benefit-cost analysis and trade policies. Journal of Political Economy 82, $1-33$.

Devarajan, S., Delfin, S., Li, H., 1999. "Quantifying the fiscal effects of trade reform: a general equilibrium model estimated for 60 countries," mimeo, The World Bank.

Diewert, W.E, Turunen-Red, A.H., Woodland, A.D., 1989. Productivity- and Pareto-improving changes in taxes and tariffs. Review of Economic Studies 56, 199-216.

Dixit, A., 1985. "Tax policy in open economies", Chapter 6 in Auerbach and Feldstein (edited): Handbook of Public Economics, vol. 1, North Holland.

Dixit, A., Norman, V., 1980. Theory of International Trade. Cambridge University Press.

Ebrill, L., Keen, M., Bodin, J., Summers, V., 2001. The Modern VAT. IMF, Washington, DC.

Emran, M.S., Stiglitz, J.E., 2000a. VAT versus trade taxes. The (In)efficiency of Indirect Tax Reform in Developing Countries (mimeo). Stanford University and Brookings Institution, Washington, DC.

Emran, M.S., Stiglitz, J.E., 2000b. Production Efficiency and Taxation of Import Substitutes in Developing Countries (mimeo). Stanford University and Brookings Institution, Washington, DC.

Emran, M.S., Stiglitz, J.E., 2002. On selective indirect tax reform in developing countries. Downloadable from SSRN Electronic Library.

Emran, M.S., Stiglitz, J.E., 2003a. Intermediate inputs and indirect tax reform (preliminary draft).

Emran, M.S., Stiglitz, J.E., 2003b. Price-neutral tax reform with an informal economy. Paper presented at NEUDC Conference 2003 at Yale University, downloadable from EconWPA (Economics Working Paper Archive) at http://econwpa.wustl.edu.

Gauthier, B., Gersovitz, M., 1993. Revenue erosion through exemption and evasion in Cameroon, 1993. Journal of Public Economics 64, 407-424.

Hatta, T., 1977. A theory of piecemeal policy recommendations. Review of Economic Studies 44, 1-21.

Hatta, T., 1986. Welfare effects of changing commodity tax rates toward uniformity. Journal of Public economics $29,99-112$.

Hatta, T., Haltiwanger, J., 1986. Tax reform and strong substitutes. International Economic Review 27, $304-315$.

Hatzipanayotou, P., Michael, M., Miller, S., 1994. Win-win indirect tax reform: a modest proposal. Economics Letters 44, 147-151 
Hinrichs, H.H., 1966. A General Theory of Tax Structure Change During Economic Development. Harvard University Press, Cambridge, MA.

Jenkins, G., Khadka, R., 1997. Value added tax policy and implementation in Singapore. International VAT Monitor 9, 35-47.

Keen, M., Ligthart, J., 2002. Coordinating tariff reduction and domestic tax reform. Journal of International Economics.

Lopez, R., Panagariya, A., 1992. On the theory of piecemeal tariff reform: the case of pure imported intermediate inputs. American Economic Review 82, 615-625.

Michael, M., Hatzipanayotou, P., Miller, M., 1993. Integrated reforms of tariffs and consumption taxes. Journal of Public Economics 52, 417-428.

Musgrave, R.A., 1969. Fiscal Systems. Yale University Press.

Newbery, D.M., 1986. On the desirability of input taxes. Economics Letters 20, 267-270.

Piggott, John, Whalley, John, 2001. VAT base broadening, self supply, and the informal sector. American Economic Review 91, 1084-1094.

Sah, R., Stiglitz, J., 1992. Peasants Versus City-Dwellers: Taxation and the Burden of Economic Development. Clarendon Press, Oxford.

Schneider, F., Enste, D., 2000. Shadow economies: size, causes, and consequences. Journal of Economic Literature 38, 77-114.

World Development Report (1988): Public Finance in Development, Part II of World Development Report 1988, published for the World Bank by Oxford University Press. 